\title{
045
}

\section{ISOLAMENTO DI F. NECROPHORUM DA EMOCOLTURA: CASO DI SDR. DI LEMIERRE}

Sartori R.', Dellantonio M.', Menghini L.G.', Caola I.', Ober P.', Caciagli P.'.

'Laboratorio di Microbiologia Ospedale di Trento

¿U.O. Anestesia e Terapia Intensiva Ospedale di Trento

\section{Introduzione:}

La Sindrome di Lemierre è una rara infezione orofaringea, complicata da una tromboflebite suppurativa della vena giugulare interna con disseminazione di emboli settici. Negli ultimi anni sono ricomparse in letteratura segnalazioni, sia pur sporadiche di tale entità clinica: l'incidenza è stata stimata in 0,8/1.000.000 abitanti per anno. L'agente eziologico usuale è il Fusobacterium necrophorum, un gram-negativo anaerobio obbligato che nell'uomo colonizza cavo orale, tratto gastrointestinale e genito-urinario.

\section{Caso Clinico:}

Ragazzo di 15 anni ricoverato in terapia intensiva per sintomatologia dolorosa addominale e inguinale intensa, shock settico e insufficienza multiorgano. Prima del ricovero ha manifestato un episodio di tonsillite che è stato trattato con claritromicina per os. con iniziale beneficio. I dati di laboratorio evidenziano leucocitosi $\left(33.000 / \mathrm{mm}^{3}\right.$ con neutrofili pari al 95\%), piastrinopenia $\left(7.000 / \mathrm{mm}^{3}\right), \mathrm{Hb} 13,8 \mathrm{gr} / \mathrm{dl}$, aumento della PCR $(45 \mathrm{mg} / \mathrm{dl})$, bilirubinemia totale $6,0 \mathrm{mg} / \mathrm{dl}$, creatinina $3,1 \mathrm{mg} / \mathrm{dl}$, urea $263 \mathrm{mg} / \mathrm{dl}$.

Successivamente l'esame TC ha documentato tumefazione e disomogeneità delle tonsille palatine con edema e imbibizione dello spazio parafaringeo destro, trombosi della vena giu- 
gulare interna ed esterna destra, aree multiple di addensamento flogistico a livello polmonare con aspetti tipici per emboli settici multipli, aree colliquative a livello del muscolo iliaco destro, dei muscoli della radice della coscia bilateralmente e versamento nella articolazione coxo-femorale sinistra.

\section{Diagnosi Batteriologica:}

Al ricovero sono state effettuate emocolture per aerobi e anaerobi. L'analisi dei campioni è stata eseguita col sistema Bactec 9240 (Becton Dickinson). Le tre emocolture per anaerobi sono risultate tutte positive per Fusobacterium necrophorum (identificazione con galleria AN-IDENT della BioMerieux) sul quale è stato eseguito l'antibiogramma con E-Test (AB BIODISK).

\section{Risultati:}

L'identificazione del batterio nell'emocoltura ha portato alla diagnosi di Sindrome di Lemierre. L'antibiogramma ha mostrato sensibilità nei confronti di Piperacillina/Tazobactam, Metronidazolo, Cefoxitina, Clindamicina, Penicillina e Imipenem.

Conclusioni:

Il riconoscimento della malattia e l'opportuna integrazione della terapia antibiotica, insieme con altri supporti (ventilatorio, CVVH, emodinamico) hanno consentito un miglioramento del quadro clinico e, dopo prolungata degenza ospedaliera, una completa risoluzione della Sindrome. 